Original Research

\title{
Life Cycle Assessment of Plastic Components in the Production of Automotive Filter
}

\author{
Hadi Sutanto $^{1 *}$, Kelvin Rumende ${ }^{2}$ \\ 'Department of Mechanical Engineering, Atma Jaya Catholic University of Indonesia, \\ Jln. Jendral Sudirman 51, Jakarta 12930, Indonesia \\ ${ }^{2}$ Department of Production Engineering, DJ., Co., Tangerang City, Indonesia
}

Received: 4 July 2021

Accepted: 20 November 2021

\begin{abstract}
Due to climate change, the demand for green production processes and green products have become important. The manufacturing industry is among the most active high environmental impact sectors. The industry should know the environmental impact of their production process. Life cycle assessment (LCA) is one method to analyze the environmental impact of the product during its lifetime, starting from material extraction, energy consumption until the end of its usage. The D.J. is a manufacturing company that produces plastic components for the automotive filter using a horizontal injection molding machine. Every year the company uses ten different types of thermoplastic materials for its products. LCA has been carried out to analyze the environmental impact of one-year production of each material using the SimaPro program as its tool. The higher environmental impact in the manufacturing stage was produced by low-density polyethylene (LDPE) material. The transportation process of material caused other effects from the location of the supplier to the factory and the energy consumed during the running machine. The results show that using the bigger transportation truck capacity, changing raw material and using lower energy machines, and managing a recycling process of automotive filters should be done to reduce the environmental impact of products.
\end{abstract}

Keywords: environmental impact, thermoplastics, automotive filter, injection molding machine, life cycle assessment, endpoint

\section{Introduction}

In recent years, manufacturing companies have faced diverse economic problems such as increasing product diversity or volume fluctuation, rapidly changing technologies, and enormous environmental and social challenges. Especially the attention to

*e-mail: hadi.sutanto@atmajaya.ac.id environmental aspects like climate change or resource depletion has become an exerting pressure for every company. Therefore, beside objectives in traditional economic production for quality, time, and cost, reducing emissions has become strategically relevant for industries. Altogether, it is necessary to strive to harmonize the requirements of sustainable development with the needs of manufacturing companies [1]. Sustainable production has been increased as a popular topic, bringing more and more attention to the industry. The interest in pollution prevention is continuously 
growing in the world. It determines more industries, including manufacturing, to develop and also implement various environmentally-friendly strategies. This has encouraged environmental policy development [2, 3] and ecological assessment methodologies to reduce the ecological footprints of product manufacturing $[4,5]$.

As a part of manufacturing processes, production processes consume raw materials and transform them into products and by-products using energy as an input. If one part of the raw material is used to create the shape and properties with added value, another part is wasted in losses, heat, and emissions. Manufacturing systems predominantly influence the environmental outcome, and therefore they can minimize the ecological performance of a company. Thus, the integration between environmental implementation and product development in industries seeks to achieve environmental improvements and reduce the harmful effects of production processes [6]. The awareness of environmental concerns has led the manufacturing industries to become proactive in designing new products, improving existing ones, and developing less emission in manufacturing processes [7]. The development of products with an environmental conscience allows industries to use tools that evaluate the production processes and quantify some potential environmental impacts [8]. The use of Life Cycle Assessment (LCA) can bring valuable results to studying ecological aspects and possible effects of a whole process, product, or service life cycle [9]. The LCA stresses the entire life cycle of the product, process, and activity. It encompasses some potential environmental impacts of a product's life cycle from the extraction and processing of the raw material, manufacturing, energy, transportation and distribution, use, reuse, maintenance, recycling, final disposal, or the cradle-to-grave process [10-12]. Therefore, LCA can be used to assess a product's, service, or process impact on the environment from the cradle to the grave [13, 14]. The ISO (2006) achieves this approach by continuing other stages that comprise the life cycle of a product, such as gate-to-gate, gate-to-grave, cradle-to-gate, and cradle-to-grave [6]. The study of LCA on the production of plastic injection molding process estimates that most of the environmental impacts are in the energy consumption due to the considerable quantity of the energy consumption involved by the raw materials extraction and production processes [15, 16]. The search for alternative materials, including recycling, is essential in the injection molding process to reduce the environmental impact [17].

In this study, the LCA quantifies and compares the gate to gate environmental loads of plastic elements in the injection molding process based on a functional unit of $1 \mathrm{~kg}$ of each component at the factory gate. The LCA model following the ISO 14040 and 14044 standards is developed for each plastic element of the automotive filter using SimaPro software [6, 18].

\section{Materials and Methods}

\section{Thermoplastics}

Thermoplastic is the primary raw material to produce many types of automotive filters in P.T. DJ., located in the Tangerang industrial area, Banten province, Indonesia. The company delivers components such as end cap, retainer, tubes, central pipe, and drain plug to build oil filters, air filters, and fuel filters used for automotive parts. To process the plastic material, the company used horizontal injection molding

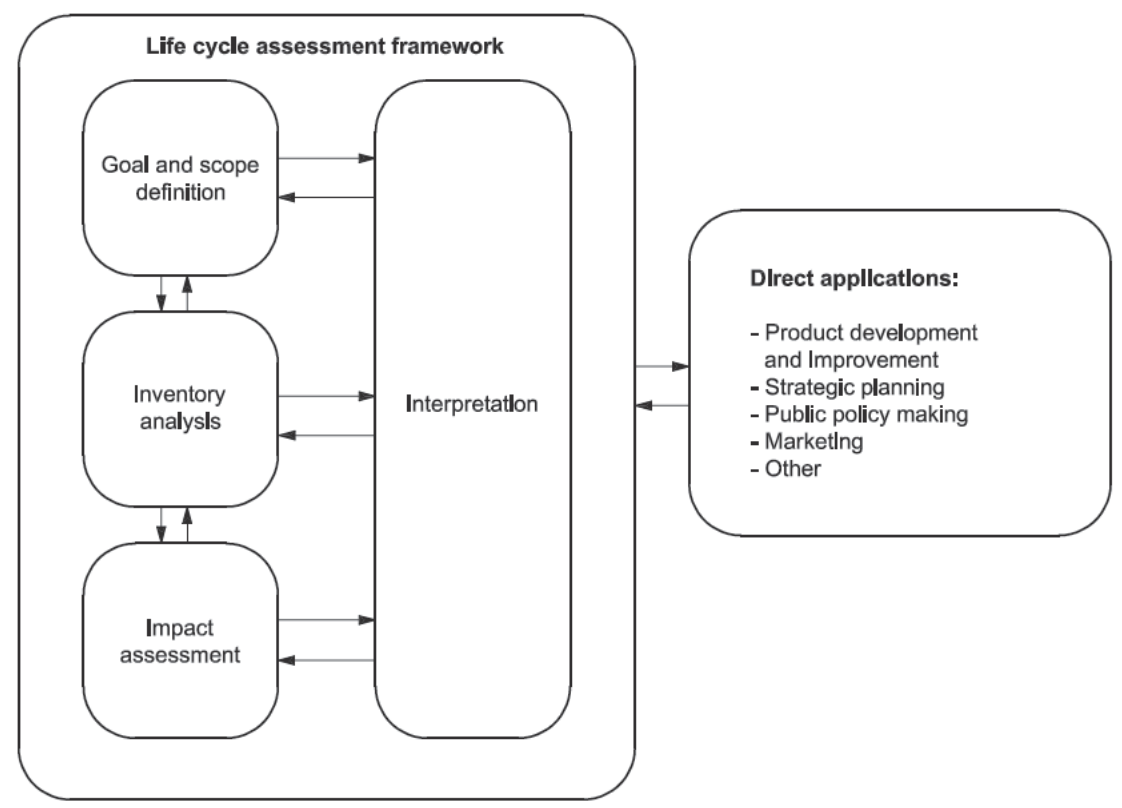

Fig. 1. The framework and stages of Life Cycle Assessment (LCA). 
Table 1. Quantity of materials and products in one-year production.

\begin{tabular}{|c|c|c|c|c|}
\hline No & Material & Main Product & Type of Filter & Quantity in 1 yr \\
\hline 1 & PA6+GF15\% & END CAP 04152-31090 & Oil Filter & 555,720 \\
\hline 2 & PA6 & RETAINER 23401-1510-1 & Fuel Filter & $3,032,719$ \\
\hline 3 & PP & SLEEVE P10-1030 & Air Filter & 89,356 \\
\hline 4 & PA66+GF30\% & RETAINER 5-13240009-0 & Fuel Filter & $1,358,206$ \\
\hline 5 & PA66+GF15\% & TUBE PLASTIK J07-6811-0 & Oil Filter & 423,290 \\
\hline 6 & ABS & END CAP 17801-61030 & Air Filter & 25,577 \\
\hline 7 & PA66 & CENTER PIPE GAV 296 / CAV 296 & Fuel Filter & 362,574 \\
\hline 8 & LDPE & CAP DIA.19.5 X T=1.2 & Fuel Filter & 184,351 \\
\hline 9 & POM & DRAIN PLUG 87457344 & Fuel Filter & 13,971 \\
\hline 10 & HIPS & END CAP 17801-58040 & Air Filter & 7,059 \\
\hline
\end{tabular}

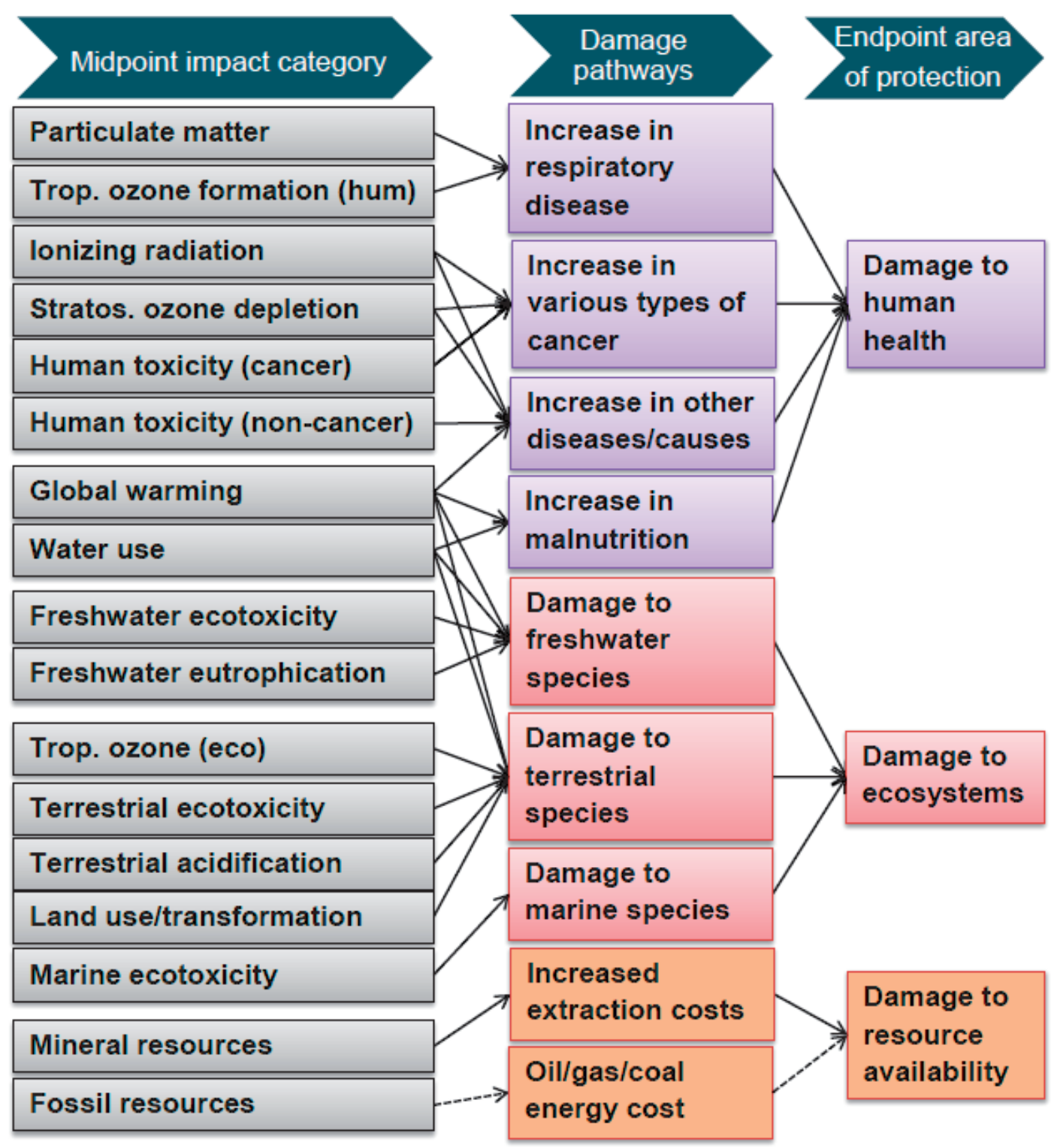

Fig. 2. Impact Category. 


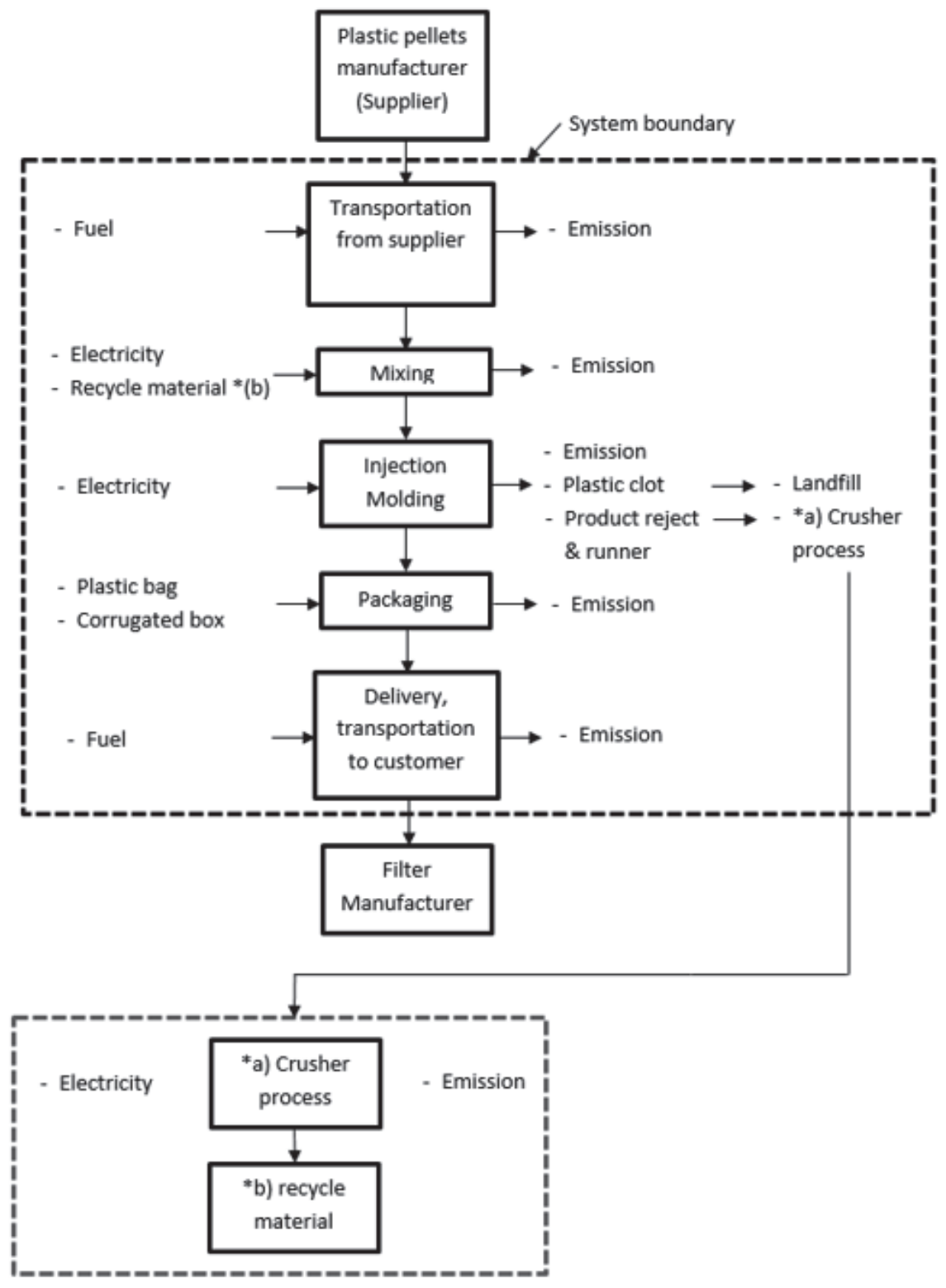

Fig. 3. LCA process of thermoplastic components.

machines. The primary material used in injection molding is an essential source of environmental impacts in the process [17]. This polymer material is fused with heat transfer and solidified when cooled without changing the chemical properties [19]. Five cycles of the process in injection molding machine include mold filling, packing, cooling phase, plasticization phase, and injection of the part [20]. The cycle of the process starts with melting a thermoplastic resin using heaters and a rotating screw. Then the volume of polymer is injected or shot into the cavity, which has the opposite form of the part that will be produced. An injection molding machine needs to have enough clamping force to avoid the melted plastic material from flowing out the mold as a defect of the injected part. The last cycle of the process after solidified is ejected the part at room temperature. Although the injection- molded plastic products process has several benefits, there is a need to use the life cycle assessment tool to reduce the negative environmental impacts of the process.

\section{Life Cycle Assessment (LCA)}

In the last two decades, many specific environmental tools and methodologies, like the life cycle assessment (LCA), have been developed that allow researchers to determine the environmental impact of different products [21] or processes [22]. The LCA is a comprehensive method with the framework and stages for an LCA shown in Figure 1. The technique consists of four steps linked is an iterative process, i.e., (1) goal and scope definition, (2) inventory analysis, (3) impact assessment, and (4) interpretation. The LCA can be 

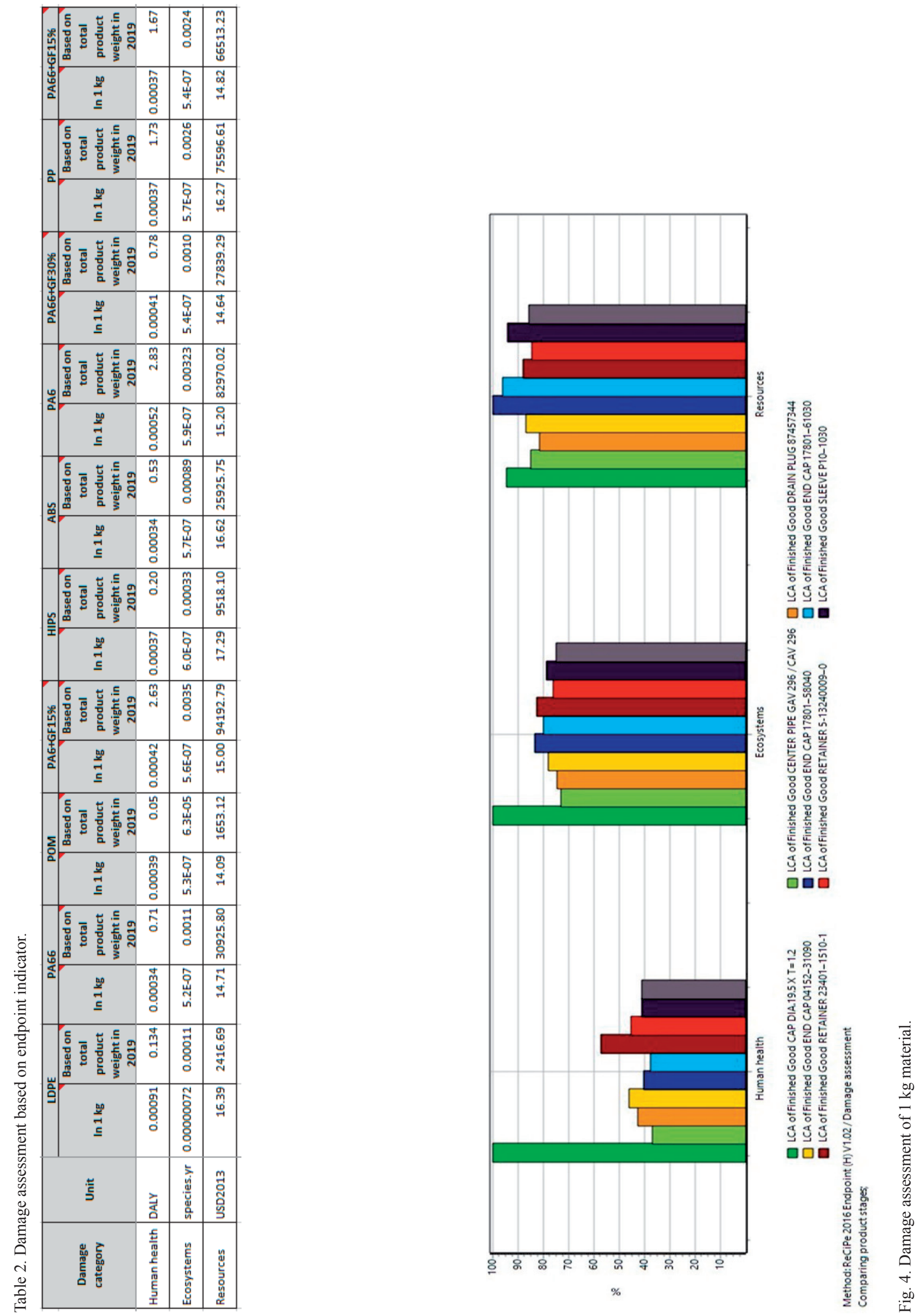


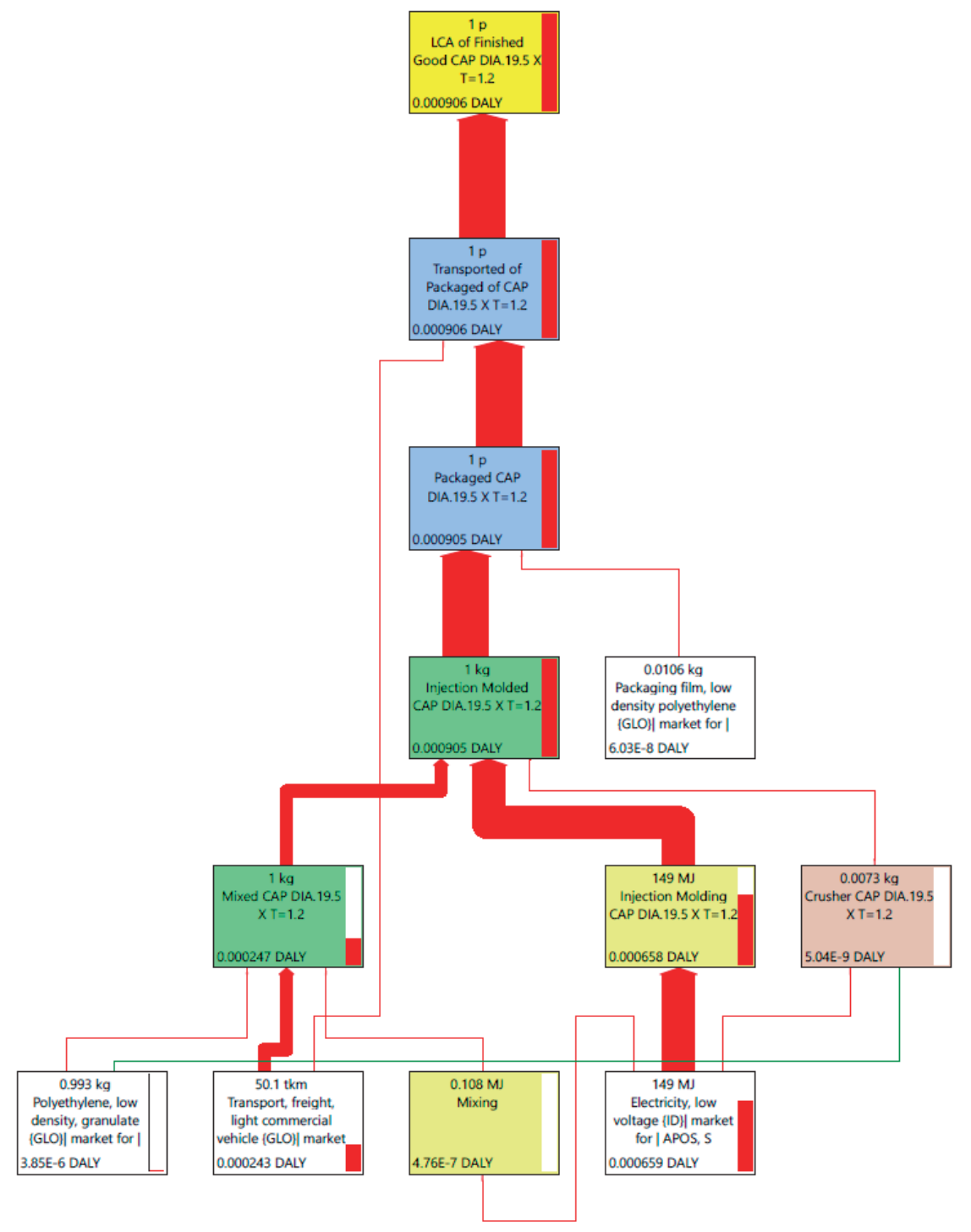

Fig. 5. Endpoint damage assessment of LDPE, Human Health.

used for product development and improvement or other purposes such as strategic planning and marketing. The iterative process in LCA permits the adjustment of previous steps because of findings in the latter assessment phases. The method of LCA is based on the consideration of all impacts on the environment, human health, and resources according to ISO 14040:2006 [6, $18]$.

\section{Goal and Scope Definition}

The goal and scope definition of the LCA initiates the basis of each study. The goal definition should contain four parts, i.e., (1) purposes, (2) reasons, (3) intended clients of the study, and (4) classification of either comparison is done or not. The scopes definition states the product system and its system boundaries and function, functional unit, and reference flow. The scope should enclose the product system to be studied and its system boundaries and function, operating unit, and reference flow. Moreover, the choice of methods is designed for allocation procedures, impact categories, and data requirements. The reference flow of function and functional unit data describes the product system's performance [6].

The goal of this assessment is to analyze the environmental impact of one-year production using thermoplastic materials. Assessment based on $1 \mathrm{~kg}$ of each raw material was converted to the total product of one-year output. The assessment impacts should cover the endpoint category, which consists of human health, ecosystems, and resources. The scope includes analyzing ten different thermoplastic materials used by the manufacturer of automotive filter products. The highest production of each material was chosen to represent the type of material. The system boundary was based on a gate-to-gate system where materials were analyzed from the receiving point of the supplier to finished products delivered to the customer. 


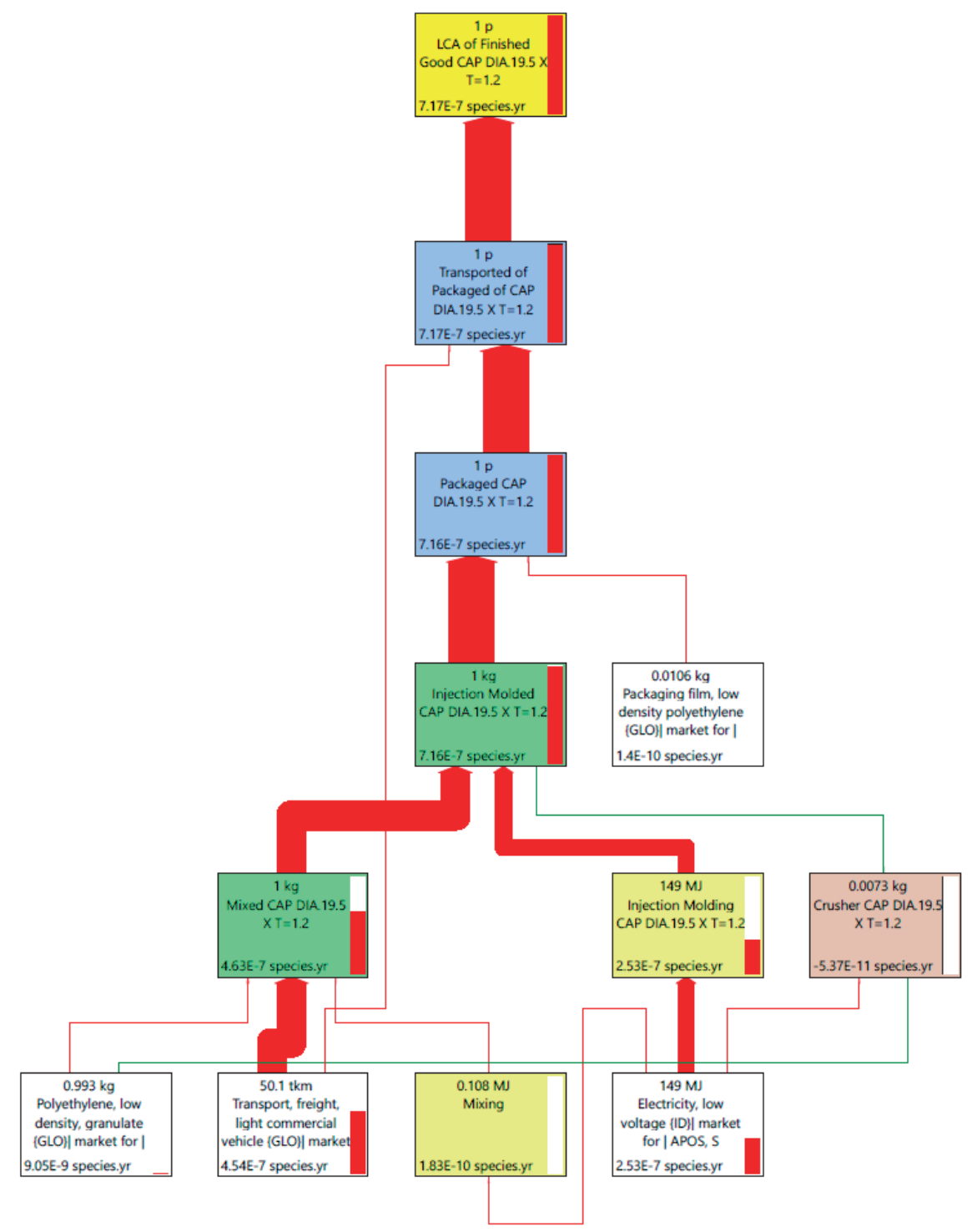

Fig. 6. Endpoint damage assessment of LDPE, Ecosystems.

\section{Inventory Analysis}

The definition of the goal and scope of LCA provides the initial plan for conducting the life cycle inventory phase when the data collection of all input and output flows occurs. There are energy and materials, products, emissions to air, waste, and discharges to water and land [6]. The outcome of the inventory analysis is a balance sheet related to all incoming and outgoing material flows. The inventory analysis usually presents an extensive data collection of the LCA and needs an iterative process that may require revisions from the goal and scope of the study. In this article, the primary data have been provided by the product's manufacturer, while available databases have been used as the source for secondary data. The data include the material consumption and production data in one year of production, as shown in Table 1. The production data was then analyzed using SimaPro Ver. 8 with the Ecoinvent database [23].

\section{Impact Assessment}

The life cycle impact assessment (LCIA) aims to evaluate the significance of potential environmental impacts using the inventory results. In general, the LCIA translates the inventory results into values of environmental damage impact using some category indicators such as climate change, acidification, eutrophication, and human or eco-toxicity [24]. The ecological effects were analyzed with ReCiPe 2016 of SimaPro 9 using the midpoint and endpoint indicators. Midpoint indicators focused only on a single environmental impact, while endpoint indicators focused on some impacts like human health, ecosystems, and resources [25]. The details of the impact category from ReCiPe 2016 are shown in Fig. 2 [26]. The LCA in this article used the endpoint indicators to analyze the environmental impact. 


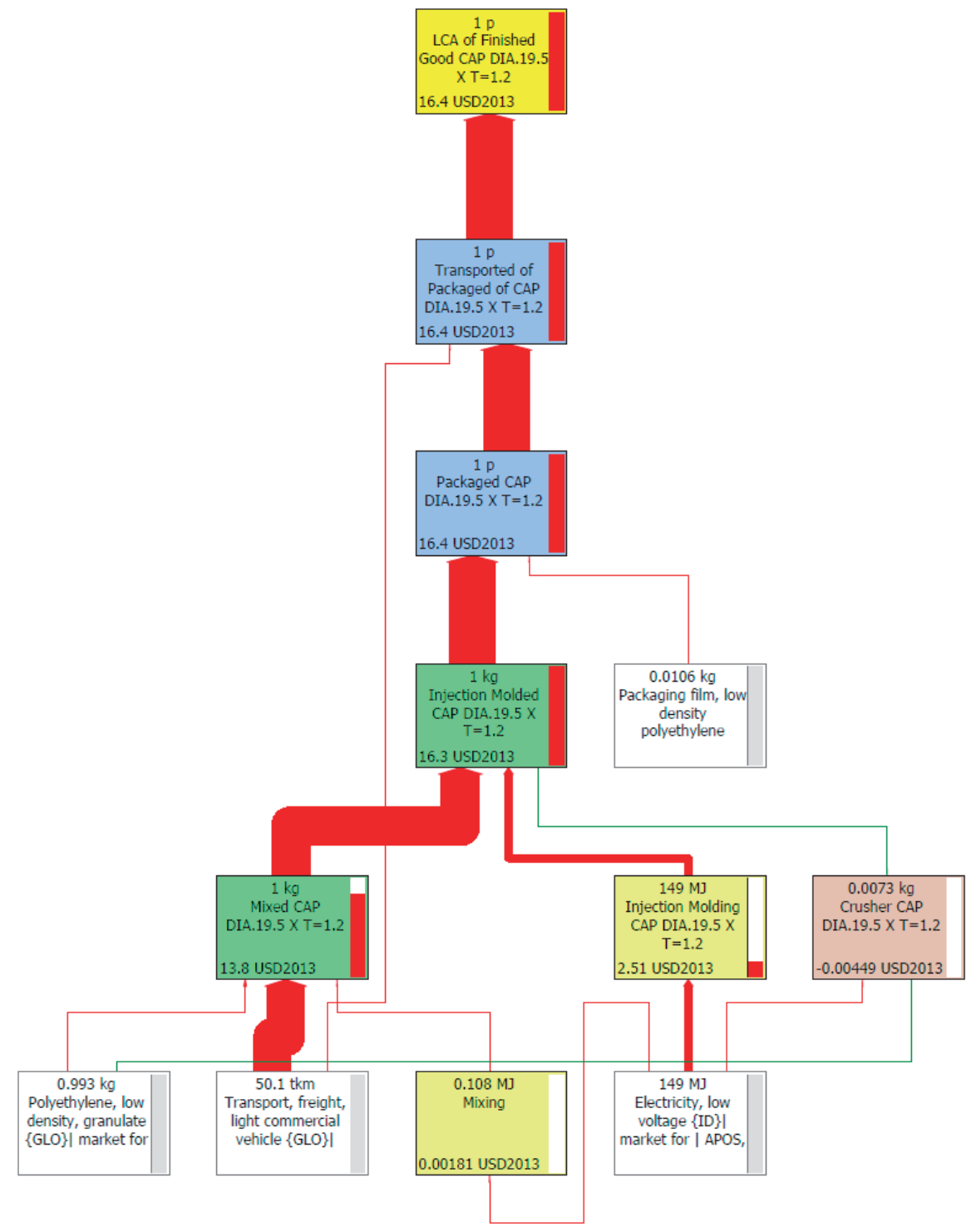

Fig. 7. Endpoint damage assessment of LDPE, Resources.

\section{Interpretation}

The interpretation is the final stage of an LCA method which consistently delivers results related to the defined goal and scope. It permits the identification of hot spots derived from the inventory analysis and impact assessment. The products should be checked for completeness, sensitivity, and consistency. Moreover, limitations are described in the interpretation stage, and it also derives recommendations and conclusions. Trade-offs between products and calculate the impact category of products were analyzed using break-even analysis [6, 27].

\section{Analyzing Data Using SimaPro}

The computer program developed by Pré Consultants B.V. or SimaPro can collect, analyze and monitor the LCA data. Furthermore, the SimaPro program can simulate the model of LCA and analyze the environmental impact of a complex LCA based on the hot spot of each process. The hot spot of the process will represent the highest value of the environmental effects, as shown in each process. SimaPro should create the waste scenario and waste treatment of products when analyzing the total life cycle of products.

Ten types of thermoplastic materials were analyzed using the SimaPro program, i.e., polyamide 6 (PA6), polyamide 6 mixed with glass fiber 15\% (PA6 + GF15\%), polypropylene (PP), acrylonitrile butadiene styrene (ABS), polyamide 66 (PA66), polyamide 66 mixed with glass fiber $15 \%$ and $30 \%$ (PA66 + GF15\% and PA66 + GF30\%), low density polyethylene (LDPE), polyoxymethylene (POM), and high impact polystyrene (HIPS). The flow process of LCA is shown in Fig. 3, where the function unit is $1 \mathrm{~kg}$ of material, and the process produces $0.73 \%$ of rejected product. 


\section{Results and Discussion}

The damage assessment results based on the endpoint indicator for ten types of thermoplastic materials are shown in Table 2. Some assumptions were used due to the limitation of data in the Eco-Invent database, for example, PA6 or PA 6 mixed with glass fiber material to produce air or oil automotive filters. As shown in Table 2 and Figure 4, the highest value of human health and ecosystems impact category are LDPE material with CAP DIA.19.5 XT $=1.2$ as the main product for the fuel filter. The human health impact category has the value of 0.00091 DALY for 1 $\mathrm{kg}$ material, but in one-year production, the result is 0.134 DALY. DALY (Disability-Adjusted Life Years) means the years lost to premature death and expressing the reduced quality of life due to illness in years.

Furthermore, in the ecosystems impact category, the highest value of LDPE material is 0.00000072 species. yr based on $1 \mathrm{~kg}$ material and 0.00011 species.yr based on the total product weight in 1 year. Species.yr means the disappearance of local species in a year. In the other endpoint of the impact category or Resources, the highest value was caused by HIPS material. The matter was equal to 17.29 USD2013 based on $1 \mathrm{~kg}$ material, and 9518.20 USD2013 based on the total product were produced in one year. This category shows additional cost in extracting resources due to resource depletion, and the unit shown is in USD2013.

The normalized total impacts (the single score) of LDPE in the Sankey diagram form are shown in Figs 5, 6, and 7. In the diagram, each box represents a material or component, and these are connected in a hierarchy by arrows whose width is proportional to the normalized impact of that material. Arrows pointing upwards (left-hand side of diagram) denotes a negative environmental impact, whereas those pointing downward denote a credit due to recycling or avoided production [28]. As shown in Figs 5 and 6, the hot spots in both diagrams were caused by the transportation process from supplier to factory and the electricity used in the production processes. In the Human Health category, the transport of light commercial vehicles was 0.000243 DALY and electricity was 0.000659 DALY, but the Ecosystem category produced 4.54E-7 species. yr for transport light commercial vehicles and 2.53E-7 species.yr for electricity. The flow diagram in Fig. 7 for the Resources category only showed 0.00181 USD2013 for mixing.

\section{Conclusions}

Based on the midpoint and endpoint damage assessment results, the highest impact is LDPE (lowdensity polyethylene) material, which produces CAP DIA.19.5 XT $=1.2$ as the main product for the fuel filter. The material flow of LDPE using Sankey diagrams of SimaPro (Figs 5, 6, and 7) showed that the hotspots were transportation processes using light commercial vehicles and energy consumption to operate the injection molding machines. Some suggestions to improve the environmental impact in the production of automotive filters, i.e., to change light vehicles to a giant truck with bigger capacity, to use low energy injection molding machines, to replace raw material with low environmental impact, and to cooperate with automotive filter manufacturer to recycle the used filter components.

\section{Conflict of Interest}

The authors declare no conflict of interest.

\section{References}

1. BRUNDTLAND COMISSIONS Our Common Future; Oxford University Press, UK., 1987.

2. SPIEGEL D.V., LINKE B.S., STAUDER J., BUCHHOLZ S., Sustainability strategies of manufacturing companies on corporate, business and operation level, International Journal of Strategic Engineering Asset Management, 2 (3), 270, 2015.

3. ANAGNOSTAKIS D., RITCHIE J.M., LIM T., CRAIG C., SPEEDIE J. The environmental impact assessment of a company's manufacturing system, Proceedings of the ASME 2015 International Design Engineering Technical Conferences \& Computers and Information Engineering Conference, Boston, MA, 2015.

4. DELOGU M., PERO F.D., ROMOLI F., PIERINI M. Life cycle assessment of a plastic air intake manifold, International Journal of Life Cycle Assessment, 20, 1429, 2015.

5. LIU Y., SYBERFELDT S., MORIS M.U., JAGSTAM M, EVERBRING J., KLOO H. Evaluating environmental impacts of production process by simulation-based life cycle assessment, $7^{\text {th }}$ Swedish Production Symposium, October, 2016.

6. ISO (International Organization for Standardization), Environmental Management-Life Cycle AssessmentPrinciples and Framework, $2^{\text {nd }}$ ed., ISO 14040:2006, ISO: Geneva, Switzerland, 2006.

7. HAROLD M.P., OGUNAIKE B.A. Process engineering in the evolving chemical industries, AIChE Journal, 46 (11), 2123,2000

8. CHANG D., LEE C., CHEN C. Review of life cycle assessment toward sustainable product development, Journal of Cleaner Production, 83, 48, 2014.

9. BARROS M.V., PIEKARSKI C.M., FRANSISCO A.C. Carbon footprint of electricity generation in Brazil: An analysis of the 2016-2026 period, Energies, 11 (6), 1, 2018.

10. LUGLIETTI R., ROSA P., TERZI S., TAISCH M. Life cycle assessment tool in product development: Environmental requirements in decision making process, Procedia CIRP, 40, 202, 2016.

11. TAGLIAFERRI C., EVANGELISTI S., ACCONCIA F., DOMENECH T., EKINS P., BARLETTA D., LETTIERI P. Life cycle assessment of future electric and hybrid 
vehicles: a cradle-to-grave systems engineering approach, Chemical Engineering Design, 112, 298, 2016.

12. GU H., BERGMAN R. Cradle-to-grave life cycle assessment of syngas electricity from woody biomass residues, Wood and Fiber Science, 19 (2), 177, 2017.

13. ALLAN K., PHILLIPS A.R. Comparative cradle-to-grave life cycle assessment of low and mid-rise mass timber buildings with equivalent structural steel alternatives, Sustainability, 13, 3401, 2021.

14. DZIKUC M., PIWORAR A. Life cycle assessment as an eco-management tool within the power industry, Polish Journal of Environmental Studies, 24 (6), 2381, 2015.

15. TELUGU M., DEL PERO F., ROMOLI F., PLERINI M. Life cycle assessment of a plastic air intake manifold, International Journal of Life Cycle Assessment, 20, 1429, 2015.

16. MATARRESE P., FONTANA A., SORLINI M., DIVIANI L., SPECHT I., MAGGI A. Estimating energy consumption of injection molding for environmental driven mold design, Journal of Cleaner Production, 168, 1505, 2017.

17. RIBEIRO I., PECAS P., HENRIQUES E. A life cycle framework to support materials selection for eco-design: A case study on biodegradable polymers, Materials and Design, 17, 300, 2013.

18. ISO (International Organization for Standardization), Environmental Management-Life Cycle AssessmentRequirements and Guidelines, $2^{\text {nd }}$ ed., ISO 14040:2006, ISO: Geneva, Switzerland, 2006.

19. CHEUNG W.M., LEONG J.Y., VICHARE P. Incorporating lean thinking and life cycle assessment to reduce environmental impacts of plastic injection moulded products, Journal of Cleaner Production, 167, 759, 2017.
20. ELDUQUE A., ELDUQUE D., JAVIERRE C., FERNANDEZ A., SANTORALIA J. Environmental impact analysis of the injection molding process: analysis of the processing of high density polyethylene parts, Journal of Cleaner Production, 108, 89, 2015.

21. OLMEZ G.M., DILEK F.B., KARANFIL T., YETIS U., The environmental impacts of iron and steel industry: a life cycle assessment study, Journal of Cleaner Production, 130, 195, 2016.

22. M.U. D., MIN M., KROHN B., MULLINS K.A., RUAN R., HILL J. Life cycle environmental impacts of wastewater-based algal biofuels, Environmental Science and Technology, 48, 11696, 2014.

23. GOEDKOOP M., OELE M., LEITJING J., PONSIOEN T., MEIJER E. SimaPro 8, Introduction to LCA with SimaPro, Pre: Amersfoort, The Netherlands, 2013.

24. HAUSCHILD M.Z., HUIJBREGTS M.A. Life cycle impact assessment, Springer, Netherlands, Dordrect, 2015.

25. DONG Y.H., THOMAS S., Comparing the midpoint and endpoint approaches based, International Journal of Life Cycle Assessment, 19, 1409, 2014.

26. NATIONAL INSTITUTE FOR PUBLIC HEALTH AND THE ENVIRONMENT, MINISTRY OF HEALTH, WELFARE AND SPORTS, ReCiPe 2016, a Harmonized Life Cycle Impact Assessment Method at Midpoint and Endpoint Level, RVIM Report 2016-0104, The Netherlands, 2016.

27. ELDUQUE A., JAVIERRE C., ELDUQUE D., FERNANDEZ A., LCI databases sensitivity analysis on the environmental impact of the injection molding process, Sustainability, 7, 3792, 2015.

28. SOUNDARAJAN K., H.O. H.K., S.U. B., Sankey diagram framework for energy and exergy flows, Applied Energy, 136, 1035, 2014. 